\title{
Caracterização de Processos Éticos instaurados contra Profissionais de Enfermagem
}

RESUMO | Objetivo: Caracterizar os processos éticos instaurados no Conselho Regional de Enfermagem de Mato Grosso do Sul, Brasil (COREN/MS). Método: trata-se de um estudo exploratório, descritivo e documental. As variáveis analisadas foram: denunciante, denunciado, desfecho do processo ético, artigos infringidos e penalidades aplicadas. A pesquisa foi aprovada pelo Comitê de Ética em Pesquisa da Universidade Federal do Mato Grosso do Sul (parecer n. ${ }^{\circ}$ 438.302). Resultados: Trinta e quatro processos éticos de 2003 a 2013 foram analisados. O COREN/MS foi o principal denunciante (47\%), a maioria dos denunciados era auxiliar de enfermagem (44\%). Houve aplicação de penalidades em 11 processos; os artigos infringidos apontaram que além de executarem práticas proibidas, houve descumprimento dos deveres e responsabilidades profissionais e, consequentemente, violação de princípios bioéticos. A penalidade mais aplicada foi advertência verbal (81\%). Conclusão: O estudo das infrações éticas é fundamental para subsidiar a tomada de decisões referentes a políticas voltadas para melhorias tanto na formação como no exercício profissional da enfermagem.

Palavras-chaves: Enfermagem; Código de Ética; Ética Profissional; Legislação de Enfermagem.

ABSTRACT | Objective: To characterize the ethical processes established at the Regional Nursing Council of Mato Grosso do Sul, Brazil (COREN/MS). Method: this is an exploratory, descriptive and documentary study. The variables analyzed were whistleblower, denounced, outcome of the ethical process, violated articles and applied penalties. A research was approved by the Research Ethics Committee of the Federal University of Mato Grosso do Sul (opinion No. 438,302). Results: Thirty-four ethical processes were analyzed from 2003 to 2013. CORE /MS was the main whistleblower (47\%), the majority of those reported in the nursing assistant era (44\%). Penalties were applied in 11 cases; the violated articles pointed out that in addition to carrying out prohibited practices, there was a breach of professional duties and obligations and, consequently, violation of bioethical principles. The most applied penalty was announced verbally ( $81 \%)$. Conclusion: The study of ethical infractions is fundamental to support decision-making related to policies aimed at improving both training and professional nursing practice.

Keywords: Nursing; Code of Ethics; Professional Ethics; Nursing Legislation.

RESUMEN | Objetivo: caracterizar los procesos éticos establecidos en el Consejo Regional de Enfermería de Mato Grosso do Sul, Brasil (COREN / MS). Método: se trata de un estudio exploratorio, descriptivo y documental. Las variables analizadas fueron: denunciante, denunciado, resultado del proceso ético, artículos violados y sanciones aplicadas. Una investigación fue aprobada por el Comité de Ética en Investigación de la Universidad Federal de Mato Grosso do Sul (opinión No. 438.302). Resultados: se analizaron Treinta y cuatro procesos éticos de 2003 a 2013. COREN/MS fue el principal denunciante (47\%), la mayoría de los reportados en la era de los auxiliares de enfermería (44\%). Se aplicaron sanciones en 11 casos; Los artículos violados señalaban que, además de llevar a cabo prácticas prohibidas, había una violación de los deberes y obligaciones profesionales y, en consecuencia, una violación de los principios bioéticos. La penalidad más aplicada se anunció verbalmente (81\%). Conclusión: El estudio de las infracciones éticas es fundamental para apoyar la toma de decisiones relacionadas con políticas destinadas a mejorar tanto la capacitación como la práctica profesional de enfermería. Descriptores: Enfermería; Código de Ética; Ética Profesional; Legislación en Enfermería.

\section{Adaiele Lucia Nogueira Vieira da Silva \\ Enfermeira. Doutoranda no curso Pós- Graduação em Saúde e Desenvolvimento na Região Centro-Oeste pela Universidade Federal de Mato Grosso do Sul (UFMS). Mestra em Enfermagem pela Universidade Federal do Mato Grosso do Sul.}

\section{Sebastião Junior Henrique Duarte \\ Enfermeiro. Doutor em Ciências da Saúde. Professor na Graduação (Três Lagoas, MS) e Mestrado (Campo Grande, MS) em Enfermagem da Universidade Federal de Mato Grosso do Sul (UFMS). Líder do Grupo de Pesquisa ASICO.}

\footnotetext{
Mariluci Camargo Ferreira da Silva Candido

Enfermeira. Doutora em Enfermagem Psiquiátrica. Professora na Graduação (Três Lagoas, MS) e Mestrado(Campo Grande, MS) em Enfermagem da Universidade Federal de Mato Grosso do Sul (UFMS).
}

\section{Roberto Della Rosa Mendez}

Enfermeiro. Doutor em Enfermagem. Professor na Graduação em Enfermagem da Universidade Federal de Mato Grosso do Sul (UFMS), Três Lagoas, MS.

\section{Richardson Miranda Machado}

Enfermeiro. Doutor em Ciências da Saúde. Professor na Graduação e Mestrado em Enfermagem da Universidade Federal de São João Del-Rei, Divinópolis, MG.

\section{Regina Maria dos Santos}

Doutora em Enfermagem. Professora na Graduação e Mestrado em Enfermagem da Universidade Federal de Alagoas (UFAL).

\section{Carla Aparecida Arena Ventura}

Bacharel em Direito. Doutora em Administração. Professora Titular do Departamento de Enfermagem Psiquiátrica e Ciências Humanas da Escola de Enfermagem de Ribeirão Preto da Universidade de São Paulo.

Recebido em: 04/03/2020

Aprovado em: 05/03/2020 


\section{INTRODUÇÃO}

o Brasil, os dilemas éticos
e morais vivenciados pela
equipe de enfermagem, bem como as situações envolvendo condutas inadequadas durante o exercício profissional, muitas vezes dão origem a processos éticos, a partir de denúncias registradas no Conselho Regional de Enfermagem em que o profissional for inscrito.

O conhecimento dos princípios bioéticos, éticos e das normas legais que regulamentam o exercício e atuação profissional é uma forte medida de segurança para os pacientes e para os profissionais, pois, é seu dever zelar pelo cumprimento das normas e, uma vez o erro cometido, ninguém pode alegar desconhecimento da Lei visando eximir-se de responsabilidade ${ }^{(1)}$.

Nesse sentido é que o Código de Ética dos Profissionais de Enfermagem (CEPE) estabelece os parâmetros éticos da prática profissional, as infrações e penalidades que devem ser aplicadas ao profissional infrator ${ }^{(2-3)}$.

O cumprimento dos princípios contidos no CEPE é fiscalizado pelo sistema formado por Conselho Federal de Enfermagem (COFEN) e Conselhos Regionais de Enfermagem (COREN), como órgãos disciplinadores do exercício profissional da enfermagem ${ }^{(4)}$.

Quando os profissionais de enfermagem se deparam com dilemas ético-morais ou infringem os princípios éticos, legais e bioéticos que norteiam a profissão, os casos denunciados são encaminhados para análise disciplinar no COREN, em que o profissional está registrado. Toda denúncia apresentada ao COREN deve respeitar o princípio de admissibilidade previsto no Código de Processo Ético Disciplinar da Enfermagem, deve haver a identificação tanto do denunciante quanto do profissional de enfermagem que cometeu a infração ética, assim como a data e o local da ocorrência, além de arrolar testemunhas e apontar seus nomes e endereços ${ }^{(5)}$.

É oportuno mencionar que o procedimento ético-disciplinar pode ser iniciado tanto por denúncia quanto por ofício. Os casos iniciados por ofício indicam que o Plenário do COREN local tomou conhecimento da ocorrência e a registrou ${ }^{(5)}$. As denúncias são submetidas para um conselheiro relator que, após averiguação prévia e análise dos fatos relatados, emite parecer consubstanciado sobre a existência ou não de indícios de infração ética.

Após a instauração do Processo Ético (PE), a análise tem por finalidade averiguar e julgar a procedência do ato praticado, imputando ou não penalidade ao profissional de enfermagem. A apuração das supostas ocorrências éticas é de responsabilidade da Comissão de Instrução e pode incluir as etapas de: sindicância prévia, oitiva dos denunciados e testemunhas, análise de documentos, além de outros procedimentos que venham a comprovar a materialidade dos fatos denunciados indicando se houve, ou não, infração ética ${ }^{(5)}$. O CEPE define infração ética como o ato cometido pelo profissional de enfermagem, omissão ou conivência que implique inobservância e/ou desobediência ao disposto no código(3).

Salienta-se que a ocorrência de dano ou lesão ao paciente acarreta responsabilidade penal e/ou civil, em que o agente causador, além de responder sobre o seu exercício profissional perante as autarquias da enfermagem, também poderá ser acionado pelo sistema judiciário brasileiro ${ }^{(2)}$.

Assim, parte-se do pressuposto de que o estudo dos PE, abarcando tanto o perfil dos denunciados, como as infrações COmetidas e as penalidades aplicadas, pode subsidiar os próprios Conselhos Regionais e Conselho Federal de Enfermagem na condução de políticas voltadas para reabilitar os profissionais infratores e ainda direcionar as necessidades de educação permanente e os benefícios da atualização do conhecimento, reforçando os princípios éticos da profissão frente às diversas atribuições exercidas pelos profissionais da categoria de enfermagem. A presente conjuntura levou à seguinte questão: Qual o perfil dos processos éticos registrados contra profissionais de enfermagem?

Nesse contexto, o objetivo deste estudo foi descrever e analisar os processos éticos instaurados junto ao Conselho Regional de Enfermagem de Mato Grosso do Sul (COREN/MS).

\section{METODOLOGIA}

Trata-se de uma investigação descritiva, retrospectiva, exploratória, documental, com abordagem baseada na Teoria Principialista de Beauchamp e Childress ${ }^{(6)}$ e no $\mathrm{CEPE}^{(3)}$. Os dados foram coletados diretamente nos arquivos do COREN/MS. Para a análise foram levantados os processos éticos instaurados na autarquia, no período de 2003 a 2013, disponíveis no sistema informatizado da instituição. Aqueles que não possuíam registro eletrônico foram excluídos, devido à dificuldade de localização.

A coleta de dados foi realizada de novembro de 2013 a janeiro de 2014. Para coleta de dados foi elaborado um instrumento com base na experiência dos pesquisadores, tomando como referência o método da análise documental. As variáveis analisadas foram: a) caracterização do denunciante; b) caracterização do denunciado (categoria profissional e idade); c) desfecho do processo ético; d) artigos infringidos; e) penalidades aplicadas.

A pesquisa foi realizada após a aprovação pelo Comitê de Ética em Pesquisa da Universidade Federal de Mato Grosso do Sul sob o parecer n. ${ }^{\circ} 438.302 / 2013$.

Primeiramente, o projeto de pesquisa foi apresentado aos Conselheiros do COREN/MS, explicando-se os objetivos e métodos do estudo. Posteriormente, foi assinado um termo de compromisso para utilização dos dados pelos pesquisadores.

Após a autorização pelo COREN/ MS e a aprovação do projeto pelo Comitê de Ética, um funcionário do COREN/ MS averiguou, no sistema informatizado, a listagem de processos éticos e os solicitou à empresa contratada para guarda dos documentos, que não ficam arquiva- 
dos na sede do COREN/MS. A coleta de dados ocorreu em uma sala reservada nas dependências da autarquia e em nenhum momento houve a retirada de documentos do local.

Para manter o compromisso do anonimato e o sigilo dos envolvidos nos processos, cada um deles foi identificado por letras e números sequenciados: E1 (Enfermeiro 1), T1 (Técnico de Enfermagem 1) e AE1 (Auxiliar de Enfermagem 1).
Foi realizada a análise descritiva dos dados, com tratamento estatístico da frequência simples e acumulada. Os resultados foram apresentados com o auxílio de tabelas e discutidos com o apoio da literatura disponibilizada em rede dos últimos cinco anos. Argumentos sustentados pelos princípios bioéticos dialogaram com os dados revelando os aspectos que podem ser alvo de programas de educação continuada.
Tabela 1. Caracterização do denunciante. Campo Grande, MS, Brasil, 2019.

\begin{tabular}{lcc} 
Denunciante & N & $\%$ \\
COREN/MS & 16 & 47,0 \\
\hline Outros órgãos (Poder Judiciário, SES, SMS, CEE) & 8 & 23,5 \\
\hline Profissional de enfermagem & 5 & 14,7 \\
\hline Instituição pública & 1 & 2,9 \\
\hline Instituição privada & 1 & 2,9 \\
\hline Outros conselhos profissionais & 1 & 2,9 \\
\hline Usuário do serviço & 1 & 2,9 \\
\hline Sindicato & 1 & 2,9 \\
\hline Total & 34 & 100,0
\end{tabular}

Tabela 2. Distribuição dos profissionais envolvidos em processos éticos apurados junto ao COREN/MS, segundo a faixa etária e categoria profissional. Campo Grande, MS, Brasil, 2019.

\begin{tabular}{lccccccccc} 
Idade & \multicolumn{2}{c}{ Enfermeiro } & \multicolumn{2}{c}{$\begin{array}{c}\text { Técnico de } \\
\text { enfermagem }\end{array}$} & \multicolumn{2}{c}{$\begin{array}{c}\text { Auxiliar de } \\
\text { enfermagem }\end{array}$} & \multicolumn{2}{c}{ Total } \\
& N & $\%$ & N & $\%$ & N & $\%$ & N & $\%$ \\
\hline 20 a 30 anos & 7 & 41,2 & 5 & 27,7 & 8 & 28,6 & 20 & 31,7 \\
\hline 31 a 40 anos & 5 & 29,4 & 10 & 55,5 & 11 & 39,3 & 26 & 41,3 \\
\hline 41 a 50 anos & 5 & 29,4 & 1 & 5,5 & 4 & 14,3 & 10 & 15,9 \\
\hline 51 anos ou mais & 0 & 0,0 & 2 & 11,1 & 5 & 17,9 & 7 & 11,1 \\
\hline Total & 17 & 100,0 & 18 & 100,0 & 28 & 100,0 & 63 & 100,0 \\
\hline
\end{tabular}

Tabela 3. Desfecho dos processos éticos apurados junto ao Conselho Regional de Enfermagem de Mato Grosso do Sul, Campo Grande, MS, Brasil, 2019.

\begin{tabular}{lcc} 
Desfecho & N & $\%$ \\
\hline Absolvição & 16 & 47,0 \\
\hline Aplicação de penalidades & 11 & 32,4 \\
\hline Conciliação & 4 & 16,8 \\
\hline Processo ético encerrado (falta de informações, PE incompleto encerrado) & 3 & 8,8 \\
\hline Total & 34 & 100,0
\end{tabular}

\section{RESULTADOS}

Foram localizados 34 processos éticos instaurados junto ao COREN/MS. Para melhor compreensão do estudo, as seguintes variáveis foram analisadas: caracterização dos denunciantes, caracterização dos profissionais de enfermagem envolvidos (categoria profissional e faixa etária). No que tange à caracterização do $\mathrm{PE}$, verificou-se o desfecho, os artigos infringidos e as penalidades aplicadas.

A Tabela 1 apresenta a caracterização dos denunciantes.

Os achados evidenciaram que $64,7 \%$ dos denunciantes pertenciam à categoria de Enfermagem, enquanto 35,3\% foram externos à profissão. $\mathrm{O}$ fato de $47 \%$ das denúncias terem sido oferecidas pelo órgão disciplinador aponta a forte atuação do COREN/MS na fiscalização do exercício profissional.

Na Tabela 2 constam dados referentes aos profissionais de enfermagem envolvidos em PE.

Nos 34 processos éticos analisados, foram denunciados 63 profissionais de enfermagem. Desses, 17 foram enfermeiros, dos quais $41,2 \%$ podem ser vistos como jovens profissionais. Dentre os técnicos e auxiliares de Enfermagem infratores éticos, a maioria expressiva tem mais de 31 anos, revelando profissionais já maduros, destacando-se que 69,4\% do total de denunciados pertenciam ao nível médio.

A Tabela 3 apresenta o desfecho dos processos éticos instaurados.

Foram aplicadas penalidades em apenas $32,4 \%$ processos éticos instaurados, enquanto $8,8 \%$ dos processos foram encerrados por não terem sido corretamente instruídos.

Para análise dos dados referentes aos artigos infringidos pelos denunciados, foi necessário respeitar a legislação em vigor no período em que a infração foi cometida. Assim, foram classificados os dados correspondentes aos processos instaurados até 2006 em conformidade com a Resolução n. ${ }^{\circ} 240 / 2000^{(7)}$ e os 
processos posteriores foram classificados conforme a Resolução COFEN n. ${ }^{\circ}$ $311 / 2007^{(3)}$. A Tabela 4 aponta a categoria dos artigos infringidos.

Os artigos infringidos apontaram o desconhecimento dos profissionais de enfermagem no que se refere aos seus deveres e responsabilidades, e revelaram a execução de práticas proibidas por parte dos profissionais de enfermagem estudados em seu exercício profissional.

Na Tabela 5 observam-se a penalidades aplicadas em 11 processos.

A advertência verbal foi a principal penalidade dentre as 11 aplicadas. Não houve casos de aplicação de multa ou suspensão. Por outro lado, é relevante ressaltar a pena de cassação para três denunciados.

\section{DISCUSSÃO}

Do total de processos éticos instaurados no Estado de Mato Grosso do Sul, a maioria $(47 \%)$ teve como denunciante o próprio COREN/MS. Esse dado revela que a autarquia tem cumprido sua função precípua de fiscalizar o exercício profissional

Tabela 4. Artigos infringidos nos processos éticos, de acordo com os direitos, deveres, responsabilidades e proibições, mediante análise da Resolução 240/2000 e da Resolução 311/2007. Campo Grande, MS, Brasil, 2019.

\begin{tabular}{lcccc} 
Artigos infringidos & \multicolumn{5}{c}{ Número de artigos infringidos } \\
& Resolução & 240/2000 & Resolução & $311 / 2007$ \\
& N & $\%$ & N & $\%$ \\
Dos direitos & 0 & 0,0 & 0 & 0 \\
\hline Deveres e responsabilidades & 16 & 72,7 & 9 & 45,0 \\
\hline Proibições & 6 & 27,3 & 11 & 55,0 \\
\hline Total & 22 & 100,0 & 20 & 100,0
\end{tabular}

Tabela 5. Penalidades aplicadas nos processos éticos, segundo categoria profissional. Campo Grande, MS, Brasil, 2019.

\begin{tabular}{lcccc} 
Tipos de penalidades & Enfermeiro & $\begin{array}{c}\text { Técnico de } \\
\text { enfermagem }\end{array}$ & $\begin{array}{c}\text { Auxiliar de } \\
\text { enfermagem }\end{array}$ & Total \\
\hline Advertência Verbal & 3 & 0 & 6 & 9 \\
\hline Multa & 0 & 0 & 0 & 0 \\
\hline Censura & 0 & 0 & 1 & 1 \\
\hline Suspensão & 0 & 0 & 0 & 0 \\
\hline Cassação & 0 & 2 & 1 & 3
\end{tabular}

bém ampará-los em aspectos legais referentes à autonomia profissional| ${ }^{(8)}$, pois é sabido que diversos fatores contribuem para a ocorrência de infrações éticas, principalmente em questões relacionadas às condições laborais, também defendidas por sindicatos, como a sobrecarga de trabalho, dupla jornada de trabalho, baixa remuneração e a recorrente escassez de recursos, tanto material quanto humano. Tais situações podem induzir à ocorrência de infrações éticas.

A literatura aponta que é dever ético dos profissionais da enfermagem evitar riscos desnecessários aos pacientes, entretanto, constitui dever legal das instituições empregadoras proporcionar condições de trabalho seguras, a fim de prevenir riscos, danos, prejuízos ou iatrogenias, decorrentes da deficiência ou insuficiência de recursos humanos e materiais ${ }^{(2,9)}$. Nesse sentido, é fundamental a fiscalização das instituições empregadoras tanto pelos sindicatos, como pelo sistema de fiscalização do exercício profissional da enfermagem e de outras instâncias jurídicas, como o Ministério Público.

Com relação à fiscalização pelos Conselhos profissionais, estes poderão expedir notificações e autos de infração, bem como promover diligências e sindicâncias. O sistema de fiscalização tem como alicerce o processo educativo, visando o estímulo aos valores éticos e a valorização do processo de trabalho em enfermagem. Deste modo, a ação de fiscalizar é tida como um importante instrumento, não apenas para combater profissionais que atuam em desrespeito à legislação pátria, mas também instituições que corroboram com essa prática ${ }^{(10-11)}$.

Os achados apontaram que os profissionais de nível médio são os que mais se envolveram em processos éticos, pois, dos 63 profissionais envolvidos, 28 eram auxiliares de enfermagem e 18 técnicos de enfermagem. Vale destacar que na época da coleta dos dados, o Estado de Mato Grosso do Sul contava com 12.873 profissionais de enfermagem de nível médio registrados no COREN/MS ${ }^{(12)}$. Por- 
tanto, constituem o maior contingente de profissionais da enfermagem, logo, é esperado que, por serem a maioria, estejam mais sujeitos a infrações éticas.

Nessa perspectiva, aponta-se a necessidade da implementação de políticas de educação continuada para todos os profissionais de enfermagem, tanto pelo Ministério da Saúde quanto pelas entidades de classe, no sentido de prevenir erros provocados pela desatualização de técnicas, pois, em que pese a precarização dos serviços de saúde devido à escassez de materiais e equipamentos, a situação é agravada quando a formação é ineficiente e de baixa qualidade ${ }^{(13)}$.

Com relação à qualidade na formação dos profissionais de enfermagem, seja de nível médio ou superior, a Associação Brasileira de Enfermagem (ABEn), lançou o projeto Movimento em Defesa da Qualidade da Formação dos Profissionais da Enfermagem, no ano de 2010.

Tratou-se de trabalho com representantes da ABEn, do COFEN e da Federação Nacional de Enfermeiros (FNE) visando elaborar as diretrizes do movimento. As entidades reivindicaram ao Ministério da Educação e Cultura (MEC) agilidade na alteração do Decreto n. ${ }^{0} 5.773$ de 2006, para que os pedidos de criação de cursos de graduação em enfermagem sejam encaminhados para apreciação no Conselho Nacional de Saúde (CNS), conforme ocorre com outros cursos da área da saúde. A iniciativa tende a ampliar a regulação da formação dos profissionais de enfermagem com qualidade ${ }^{(14)}$.

Além da formação adequada, é imprescindível destacar a importância de ações de reciclagem assim como a reabilitação dos infratores, pois é direito do profissional de enfermagem atualizar$-\mathrm{se}^{(3)}$, porém cabe à instituição empregadora e ao conselho de classe implementar essa prática.

Com relação à faixa etária dos envolvidos, a maior frequência esteve entre os adultos jovens, provavelmente profissionais com pouca experiência na enfermagem, pois ao observar o cometimento de infrações por profissionais por nível de escolaridade, constata-se que dentre os enfermeiros, a maioria dos infratores situava-se na faixa de 20 a 30 anos de idade. Esse dado retoma a discussão a respeito da formação. Se são adultos jovens, provavelmente recém-formados, é preciso atentar para a formação que atenda, minimamente, as diretrizes curriculares nacionais para os cursos de graduação em enfermagem, consideradas essenciais na formação do perfil profissional qualificado.

No que se refere ao desfecho dos processos éticos (PE) instaurados, quase todos foram encerrados e arquivados, pois os envolvidos foram absolvidos. Após a averiguação, foi constatado que não houve indícios de infração ética nos processos instaurados ou os elementos apresentados não foram suficientes para sustentar a ocorrência de infração ética. Nestes também devem ser considerados aqueles que foram instaurados devido a pendências financeiras junto à autarquia e foram encerrados e arquivados após a regularização da dívida. Desse modo, constata-se que os direitos constitucionais foram assegurados aos envolvidos, tanto no que se refere à ampla defesa e ao contraditório, como a absolvição por falta de elementos condenatórios.

Quanto aos profissionais infratores, houve aplicação de penalidades previstas pelo CEPE, e a execução das penalidades impostas se processou na forma estabelecida nas decisões ou acórdãos, sendo registradas no prontuário do profissional infrator $^{(5)}$. Com isso, o COREN/MS demonstrou a imparcialidade na defesa da sociedade.

O Código de Processo Ético-Disciplinar da Enfermagem menciona que, nos casos que não resultaram em óbito, podem ser realizadas audiências prévias de conciliação entre denunciado e denunciante, possibilitando o arquivamento mediante retratação ou ajustamento de conduta. No entanto, nos casos em que não haja conciliação e se houver indícios de infração ética, é instaurado um processo ético, respeitando-se todo o processo de julgamento, apresentação de recurso e aplicação de penalidades, conforme indica o Código citado(5).

Os dados apontam que houve PE arquivados e encerrados, porém em situação de incompletude. Apesar de haver o Código de Processo Ético-Disciplinar da Enfermagem para orientar a condução do $P E$, percebe-se que há necessidade de maior rigor na averiguação da infração ética, seja na oitiva dos envolvidos ou na juntada de documentos, até o final do processo $^{(5)}$.

No que tange aos artigos infringidos, é válido salientar que foi utilizada também a Resolução n. ${ }^{\circ}$ 240/2000(7) , revogada pela Resolução n. ${ }^{\circ}$ 311/2007(3) , devido à data de instauração dos processos. Desse modo, todos os processos instaurados antes de 08 de fevereiro 2007 foram analisados à luz dos preceitos contidos na Resolução n. ${ }^{\circ}$ 240/2000 (7), e a discussão dos artigos infringidos. Será feita a discussão dos artigos infringidos em cada resolução separadamente.

Os artigos infringidos na Resolução n. ${ }^{\circ} 240 / 2000^{(7)}$ foram: 16, 21, 22, 26, $38,47,48,68,69,70,71,72,74$. Os artigos infringidos relacionados às proibições foram os artigos 47 e 48, que se referem à administração e prescrição de medicamentos. Apesar das inúmeras discussões sobre a administração e a prescrição de medicamentos, o estudo apontou que ainda são recorrentes as ocorrências éticas relacionadas ao tratamento. Nesse contexto, são fundamentais os treinamentos e capacitações com intuito de atualizar e reciclar os profissionais de enfermagem, a fim de evitar a troca inadvertida de medicação, a via de administração ou dosagem errada, erros estes geralmente associados à falta de atenção e à falta de conhecimento do profissional ${ }^{(16)}$. Desse modo, o aprimoramento profissional é essencial para melhorar a qualidade da assistência de enfermagem, oferecendo um serviço com segurança tanto para o paciente quanto para a equipe.

Os PE instaurados após 2007 foram norteados pela Resolução n. ${ }^{\circ} 311 / 2007^{(3)}$. Os artigos infringidos foram: 5, 7, 9, 12, 
$18,21,28,30,32,38,39,48,49,56,59$, 73 e 77 . A maioria dos artigos referia-se às proibições, visto que um dos processos tratava da atuação de duas técnicas e um auxiliar de enfermagem em práticas de abortamento. O Código Penal Brasileiro considera o aborto como um dos crimes contra a vida. O artigo 126 do Código Penal define como crime a provocação do aborto, mesmo com o consentimento da gestante, com pena de reclusão que varia de 1 a 4 anos; já o CEPE em seu artigo 28 define como proibições o ato de provocar aborto ou cooperar em prática destinada a interromper a gestação ${ }^{(3)}$.

Os dados apontam as infrações presentes na prática cotidiana dos profissionais de enfermagem. Além do preparo técnico e de atualizações constantes, é vital que profissionais desenvolvam compromisso ético, para conhecer seus direitos, deveres, responsabilidades e o que é proibido no exercício profissional ${ }^{(9)}$.

Sob a ótica da Teoria Principialista de Beauchamp e Childress $^{(6)}$ alguns princípios bioéticos foram violados. A teoria defende quatro princípios, o princípio da autonomia, da beneficência, da não maleficência e da justiça. Na análise dos PE instaurados junto ao COREN/MS, verificou-se que dois princípios bioéticos foram violados: o princípio da beneficência e o da não maleficência. O princípio da beneficência relaciona-se ao dever de ajudar aos outros, de fazer ou promover o bem, de buscar o máximo de benefícios ao outro ou até mesmo agir eticamente, reduzindo ao mínimo os danos e riscos. Já o princípio da não maleficência implica no dever de privar-se de fazer qualquer mal para os pacientes, de causar danos ou colocá-los em risco(6).

É imperativa uma atitude voltada para a discussão e reflexão constantes dos princípios bioéticos e conflitos morais presentes na prática da enfermagem, com intuito de interligar o cuidado técnico com o cuidado pautado nos princípios éticos e bioéticos, numa perspectiva do cuidado seguro e legal. Dessa forma, é necessário desenvolver competências profissionais que primem pelo zelo dos princípios éticos e bioéticos, assegurando a assistência de enfermagem livre de riscos ou danos tanto para os pacientes quanto para a equipe ${ }^{(15)}$.
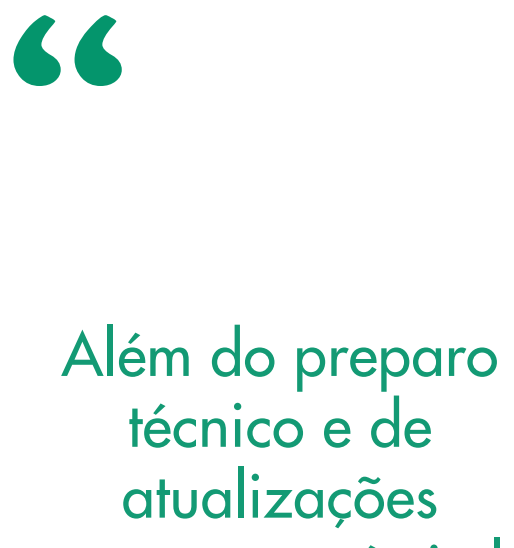
constantes, é vital que profissionais desenvolvam compromisso ético, para conhecer seus direitos, deveres, responsabilidades e o que é proibido no exercício profissional( $^{(9)}$.

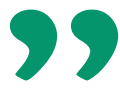

Com relação aos 11 processos em que houve aplicação de penalidade; em nove foi aplicada a advertência verbal, que consiste na admoestação ao infrator, de forma reservada, a qual é registrada em seu prontuário na presença de duas teste- munhas. Já a censura foi atribuída apenas em um processo e consiste em repreensão que é divulgada nas publicações oficiais dos Conselhos Federal e Regional de Enfermagem e em jornais de grande circulação. Não houve caso de aplicação de multa ou suspensão. Em um PE houve a cassação do direito ao exercício profissional de três profissionais do nível médio. A cassação consiste na perda do direito ao exercício da enfermagem e é divulgada nas publicações dos Conselhos Federal e Regional de Enfermagem e em jornais de grande circulação. Salienta-se que a cassação do exercício profissional é prerrogativa do COFEN ${ }^{(3)}$.

Destaca-se que, no Brasil, a força de trabalho da enfermagem é constituída por mais de dois milhões de trabalhadores, que estão inseridos nos diversos serviços de saúde presentes em todo o território nacional. No seu trabalho cotidiano, a enfermagem sustenta um vínculo direto com os usuários e seus familiares ${ }^{(17)}$, o que implica na responsabilidade e compromisso de protegê-los de erros e negligências, qualquer que seja a sua origem ${ }^{(10,18)}$.

Os achados exemplificam a dimensão de um problema crescente, pois além de estarem executando ações que são proibidas no exercício profissional, violando princípios bioéticos, há desobediência aos princípios éticos, especialmente no que se refere ao descumprimento dos deveres e responsabilidades profissionais, seja com os pacientes, com a equipe ou com o próprio conselho de classe, como nos casos de inadimplência. Salienta-se que, nos casos em que houve lesão ou dano ao paciente, o profissional de enfermagem envolvido em tal ato, além de ter sido punido nos tribunais de ética, também foi julgado pelo sistema judiciário brasileiro.

Nesse sentido, é de suma importância que os profissionais de enfermagem conheçam, interpretem e apliquem as legislações pertinentes ao exercício da enfermagem durante a sua prática cotidiana, respeitando assim os princípios bioéticos e as prerrogativas profissionais estipuladas pela lei. Outra questão que 
precisa ser considerada é a obrigação das autarquias da enfermagem e das instituições empregadoras de prover, promover e gerenciar as condições de trabalho e riscos a que os clientes e os profissionais de enfermagem estão expostos ${ }^{(9)}$.

As denúncias contra profissionais de enfermagem sobre a ocorrência de danos à saúde por ações culposas decorrentes de imperícia, negligência e imprudência estão se tornando cada vez mais frequentes, nos distritos policiais e fóruns cíveis e criminais. Nesse cenário, o CEPE constitui o balizamento da prática profissional de todos que exercem a enfermagem, seja na assistência, na pesquisa, no ensino ou na administração, e a desobediência e/ou inobservância dos princípios contidos neste código, são passíveis de penalidades ${ }^{(2,19)}$.

É notório que o reconhecimento social das categorias de enfermagem deve passar tanto pela valorização das competências técnicas quanto éticas e legais, assim como pela defesa intransigente dos direitos e deveres de cada categoria ${ }^{(9)}$. Desse modo, é imprescindível conhecer a realidade do cotidiano destes profissionais no que tange aos processos éticos instaurados.

\section{CONCLUSÃO}

Embora limitado pelo período de mais de um ano decorrido entre a coleta dos dados e a publicação, este estudo serve de motivação para outros estudos que deem continuidade à pesquisa envolvendo os processos éticos instaurados pelo Conselho Regional de Enfermagem do Mato Grosso do Sul, Brasil, bem como, a replicação do estudo em outros regionais.
Por meio da descrição dos processos éticos instaurados pelo COREN/MS, ficou evidente que quase todas as infrações éticas apontadas são passíveis de prevenção, pois são oriundas do despreparo técnico e da falta de atenção aos princípios éticos e bioéticos.

$\mathrm{Na}$ análise dos processos éticos, observou-se a necessidade da implantação de políticas de educação permanente dos profissionais de enfermagem, tendo em vista o crescente surgimento de recursos tecnológicos no setor saúde, o que requer o desenvolvimento de habilidades muitas vezes não aprendidas na formação.

Todavia cabe, também, ao conselho de classe a condução de políticas de reabilitação para os profissionais infratores, promovendo a reinserção de profissionais qualificados ao mercado de trabalho.

\section{Referências}

1. Brasil. Decreto-Lei $n .^{\circ} 4.657$, de 4 de setembro de 1942. Lei de Introdução às normas do Direito Brasileiro. Diário Oficial da União, Brasília, 9 set. 1942. Seção 1, p. 13635.

2. Oguisso T, Schmidt MJ. 0 exercício da enfermagem: uma abordagem ético-legal. 3. ed. at. ampl. Rio de Janeiro: Guanabara Koogan. 2013. 3. Conselho Federal de Enfermagem (BR). Resolução COFEN n. ${ }^{\circ}$ 311, de 8 de fevereiro de 2007. Aprova a reformulação do Código de Ética dos Profissionais de Enfermagem. Código de ética dos profissionais de enfermagem [Internet]. Brasília; 2007 [citado 2019 jan. 5]. Disponível em: http://novo.portalcofen.gov.br/resoluo-cofen-3112007_4345.html

4. Brasil. Lei $n .^{\circ}$ 5.905, de 12 de julho de 1973. Dispõe sobre a criação dos Conselhos Federal e Regionais de Enfermagem e dá outras providências. Diário Oficial da União, Brasília, 13 jul. 1973. Seção 1, p.6825.

5. Conselho Federal de Enfermagem (BR). Resolução COFEN n. ${ }^{\circ} 370$, de 3 de novembro de 2010. Aprova o Código de Processo Ético dos Conselhos de Enfermagem [Internet]. Brasilia; 2010 [citado 2019 jan. 10]. Disponivel em: http://www.cofen.gov.br/wp-content/uploads/2012/03/ resolucao370_10anexo.pdf

6. Beauchamp TL, Childress JF. Princípios de ética biomédica. 2. ed. Trad. Luciana Pudenzi. São Paulo: Edições Loyola; 2011.

7. Conselho Federal de Enfermagem (BR). Resolução COFEN n. ${ }^{\circ} 240$ de 30 de agosto de 2000. Revogada pela Resolução ${ }^{0} 311 / 2007$. Aprova o Código de Ética dos Profissionais de Enfermagem e dá outras providências [Internet]. Brasília; 2000 [2019 citado jan 20] Disponível em: http://www.cofen.gov.br/resoluo-cofen-2402000-revogada-pela-resoluo-cofen-3112007_4280.html

8. Avila LI, Silveira RS, Lunardi VL, Fernandes GFM, Mancia JR, Silveira JT. Implications of the visibility of professional nursing practices. Rev Gaucha Enferm [Internet]. 2013 [2019 citado jan 20];34(3):102-9. DOI: http://dx.doi.org/10.1590/S1983-14472013000300013

9. Oguisso T, organizadora. Trajetória histórica e legal da enfermagem. 2. ed. Barueri: Manole; 2007.

10. Costa EO, Germano RM, Medeiros SM. A fiscalização do exercício profissional no conselho federal de enfermagem. REME Rev Min Enferm [Internet]. 2012 [2019 citado jan 20];18(1):208-12. DOI: http:// www.dx.doi.org/10.5935/1415-2762.20140016

11. Conselho Federal de Enfermagem (BR). Manual de Fiscalização do COFEN/Conselhos Regionais, 2011.

12. Conselho Regional de Enfermagem de Mato Grosso Do Sul. Ofício Gabinete COREN-MS n. ${ }^{\circ} 273$ de 21 de março de 2012.

13. Silva ACAB, Silva GTR, Silva RMO, Vieira SL, Santana MS. Secondary professional education: characterization of scientific production in graduate studies. Acta Paul Enferm [Internet]. 2013 [2019 citado jan 20];26(5):499-505. DOI: http://dx.doi.org/10.1590/S010321002013000500015.

14. Teixeira E, Cabral I. 0 movimento em defesa da qualidade da formação dos profissionais da enfermagem e o trabalho da ABEn área da educação. Rev Bras Enferm. 2011;64(2):223.

15, Silva ALNV, Candido MCFS, Duarte SJH, Sampaio ATL, Santos RM. Relationship between length of service and ethics violations in nursing. Rev enferm UERJ [Internet]. 2018 [2019 citado jan 20]; 26:e23058. DOI: http://dx.doi.org/10.12957/reuerj.2018.23058.

16. Schneider DG, Ramos FRS. Nursing ethical processes in the State of Santa Catarina: characterization of factual elements. Rev Lat-Am Enfermagem [Internet]. 2012 [2019 citado jan 20];20(4):744-52. DOI: http://dx.doi.org/10.1590/S0104-11692012000400015

17. Sena RR, Silva KL. Nursing as a supportive partner of the Brazilian National Health System. Rev Esc Enferm USP [Internet]. 2011 [2019 citado jan 20]; 25(n.esp):1792-6. DOI: http://dx.doi.org/10.1590/S008062342011000800027.

18. Silva ALNV da, Silva MCF da, Duarte SJrH et al. Violations and ethical incidents committed by nursing professionals: an integrative review. J Nurs UFPE on-line [Internet]. 2015 Jan. [2019 citado jan 20]; 9(1):201-11. DOI:10.5205/reuol.6817-60679-1-ED.0901201528.

19. Silva ALNV da, Silva MCF da, Duarte SJH, Santos MS dos. Complaints filed against nursing professionals: Mapping a Brazilian reality. Nursing Ethics [Internet] 2016 [cited 2019 Jan. 10]; 8(23). DOI: https:// doi.org/10.1177/0969733015587777 